\title{
DEMOCRACIA, PODER CONSTITUYENTE O REFORMA CONSTITUCIONAL Y SUS IMPLICANCIAS JURÍDICAS EN EL PROCESO POLÍTICO DE CAMBIO CONSTITUCIONAL EN CHILE
}

\author{
HUMBERTO NOGUEIRA ALCALÁ \\ Catedrático de Derecho Constitucional \\ Universidad de Talca1
}

\section{SUMARIO}

I. La Democracia como base común. II. El poder constituyente y la reforma de la Constitución. III. La reforma de la Constitución chilena vigente.

El artículo que presentamos, en forma breve como se nos ha solicitado, expone y analiza las vinculaciones entre democracia, poder constituyente originario e instituido y el proceso de cambio constitucional en actual desarrollo en Chile, teniendo presente la experiencia comparada, algunas dimensiones dogmáticas de derecho constitucional y las diversas etapas diseñadas para concretar en Chile dicho proceso para viabilizar un nuevo texto constitucional.

\section{LA DEMOCRACIA COMO BASE COMÚN}

Puede señalarse que en materia de concepciones de la democracia hay muchas aproximaciones, sin embargo, consideramos que la democracia contemporánea establece algunos atributos permanentes básicos para identificarla, que están dados por ciertos valores, principios y reglas de procedimiento ${ }^{2}$.

1 Director Ejecutivo del Centro de Estudios Constitucionales, Presidente de la Asociación Chilena de Derecho Constitucional y Vicepresidente del Instituto Iberoamericano de Derecho Procesal Constitucional.

2 Nogueira, H., Derecho constitucional chileno.Tomo I. Santiago, Ed. Abeledo Perrot — Thomson Reuters, 2013, pp. 598-599. 
Los valores están dados por el respeto de la dignidad de la persona humana, la libertad y la igualdad esencial de todas las personas.

Los principios están dados por la autodeterminación del pueblo y el respeto y garantía de los derechos humanos en cuanto derechos universales, indivisibles, complementarios, inalienables e imprescriptibles.

Las reglas de procedimiento están conformadas por el gobierno de la mayoría en el respeto de los derechos humanos de todos; la exclusión de la violencia como método de acción política; el pluralismo ideológico y político, las elecciones periódicas libres, informadas y transparentes, la distribución del poder del Estado en órganos con diferentes competencias sometidos a controles jurídicos y políticos; la posibilidad de alternancia en el gobierno; la independencia de la judicatura, la responsabilidad jurídica y política de los gobernantes, la autonomía de los cuerpos intermedios de la sociedad y la vigencia de un Estado Constitucional, que distingue entre poder constituyente y poderes constituidos, que explicita la supremacía constitucional y establece controles jurisdiccionales de constitucionalidad.

Tal perspectiva es asumida por los estados latinoamericanos al firmar la Carta democrática interamericana en 2001, que precisa los derechos fundamentales y humanos como parte medular del régimen democrático.

\section{EL PODER CONSTITUYENTE Y LA REFORMA DE LA CONSTITUCIÓN}

Al realizar algunas consideraciones sobre la materia es indispensable distinguir entre el ejercicio del poder constituyente originario y el poder instituido de reforma constitucional.

\section{El poder constituyente originario}

El poder constituyente es la potencia originaria, extraordinaria y autónoma del cuerpo político de una sociedad que dicta las normas fundamentales para la organización y funcionamiento de su convivencia política y jurídica, pudiendo sustentar o cancelar la Constitución en su pretensión de validez. Esta potestad es la «suprema capacidad y dominio del pueblo sobre sí mismo al darse por su propia voluntad una organización política y un ordenamiento jurídico» ${ }^{3}$.

Así el poder constituyente en cuanto potestad originaria, no deriva de ningún otro poder jurídico interno preexistente. El poder constituyente es así un

3 Sánchez Viamonte, C., El poder constituyente. Buenos Aires. Ed. bibliográfica argentina, 1957, p. 564. 
poder pre-jurídico y por ello ilimitado ${ }^{4}$. El poder constituyente originario es aquel que organiza y da forma jurídica a un Estado o permite que este vuelva a refundar su orden jurídico luego de un proceso revolucionario o de un golpe de Estado, o de una decisión pacífica del cuerpo político de la sociedad, constituyendo una erupción de la libertad política del pueblo para dotarse de un nuevo orden jurídico fundamental.

El poder constituyente originario permanece siempre como un poder plenamente autónomo para ordenar y reordenar la convivencia básica de una sociedad política a través de la Constitución Política, cuando así lo decida autónomamente el cuerpo político de la sociedad, teniendo libertad para configurar dicho ordenamiento jurídico.

El poder constituyente originario es la fuente de todo derecho positivo interno.

Las limitaciones del poder constituyente en el siglo XXI, conforme a la idea de derecho válida vigente, están dadas por los principios imperativos del derecho internacional o normas de ius cogens, las vinculaciones del Estado por el derecho convencional internacional ratificado y vigente y la salvaguarda de los derechos humanos fundamentales de las personas.

El poder constituyente originario solo tiene potestad omnímoda respecto de normas internas preconstitucionales, pero no puede alterar las normas internacionales que le son aplicables que condicionan la acción válida y legítima del poder constituyente como son por ejemplo las normas de ius cogens o las normas de tratados internacionales que han determinado las fronteras del Estado o las del derecho convencional internacional incorporadas válidamente al derecho interno y que no son susceptibles de denuncia o revisión.

La decisión de un constituyente de dotar de aplicabilidad irreversible sistemas normativos internacionales o supranacionales limita el margen de actuación de los poderes constituyentes posteriores, generando un orden jurídico al que las pretensiones innovadoras de un nuevo constituyente no pueden afectar.

En este sentido, puede sostenerse con Requejo Pagés que, «el poder constituyente se diluye históricamente en tantos poderes cuantos en el pasado hayan decidido la integración de sistemas a los que los sucesivos poderes de Constitución no pueden ya desproveer de su condición de aplicables» ${ }^{5}$.

A su vez existe una unidad intrínseca entre poder constituyente y poder popular, entendiendo este último como el poder que emana del cuerpo político de la sociedad, cuerpo político que tiene el derecho básico y esencial de gobernarse a sí mismo y el derecho a la plena autonomía.

4 De Vega García, P., La reforma constitucional y la problemática del poder constituyente, Madrid, Tecnos, 1985 , pp. 24 y ss.

5 Requejo Pagés, J.L., Las normas preconstitucionales y el mito del poder constituyente. Madrid, CEPC, 1998 , p. 57. 
En un sistema constitucional democrático ninguna fracción del pueblo puede arrogarse, ni aún a pretexto de circunstancias extraordinarias, la representación del cuerpo político de la sociedad, ni sustituirlo. El cuerpo político de la sociedad tiene el derecho inalienable a auto determinarse política y jurídicamente. No hay en puridad voluntad auténtica y legitima del pueblo si no es una expresión organizada y democrática del cuerpo político de la sociedad, compuesto de ciudadanos libres e iguales, dotados del derecho de participar y decidir el ordenamiento jurídico-político en el cual desean vivir. La Constitución no es tal si no se encuentra en armonía con su fundamento democrático y no respeta y garantiza los derechos humanos.

La obra de un nuevo poder constituyente originario es así, la expresión formalizada de una potestad constituyente limitada que expresa la idea de derecho válida y vigente en la sociedad.

La Constitución requiere de la adhesión y acatamiento generalizado de la ciudadanía, tanto a nivel de conciencia generalizada como de conductas concretas de los diversos actores sociales y componentes de la sociedad ${ }^{6}$. El ordenamiento constitucional más que cualquier otro requiere de adhesión y sostenimiento por la colectividad, su validez está estrechamente vinculado a su eficacia y ésta a la adhesión de los ciudadanos y los diversos sectores que integran la sociedad. Una Constitución que carece de sustento y adhesión difundida en los miembros de la sociedad está destinada a durar poco, sólo mientras exista la fuerza que la impone.

Una Constitución solo tendrá durabilidad si ella es obra de la participación y adhesión de los diversos sectores que integran la sociedad política y el conjunto de la colectividad la hace suya, ella no permanecerá si es obra sólo de una parte del cuerpo político de la sociedad, solo la adhesión sustantiva del conjunto de la sociedad es garantía de eficacia de las normas constitucionales y de su perdurabilidad, como asimismo otorga a los gobernantes la autoridad para exigir legítimamente su acatamiento.

Como señala Stern, Lo decisivo continúa siendo aclarar la transición del acto político a la norma jurídica. La voluntad, el mandato sólo puede convertirse en derecho, si es seguido, si es reconocido, si es aceptado («consentido») como algo que debe tener vigencia.La Constitución es, pues, lo normado por la voluntad constituyente y lo reconocido como vinculante por los sometidos a la norma ${ }^{7}$. Esta aceptación es algo que tiene que producirse, como ha respondido con razón H. Heller a C. Schmitt.

A su vez, Heller sostendrá que «la creación de normas por el Estado, como ya lo observó Bülow (...) no crea desde luego un derecho válido, sino solo el plan de un derecho que se desea para el futuro ... Esta oferta que el legislador hace a

6 Ver Díaz Ricci, S., Teoría de la reforma constitucional. Buenos Aires, Ed. Universidad Autónoma de México, Universidad Complutense y Ediar, 2004, p. 123.

7 Stern, K., El derecho del Estado de la República Federal Alemana.Madrid, CEC, 1997, p. 13. 
los destinatarios de la norma sólo produce derecho vigente en la medida que las normas 'salen del papel para confirmarse en la vida humana como poder ${ }^{8}$.

Mortati dirá que «el poder constituyente está válidamente fundado cuando llegue a colocarse como fuerza ordenada a un fin y al pretender obediencia, y esta sea de hecho prestada en término medio»?

La función constituyente se concreta en un proceso en que en una primera etapa implica el desarrollo de una iniciativa constituyente que se expresa y que busca ser asumida por fuerzas sociales y políticas.

En una segunda etapa los diversos grupos y sus propuestas constituyentes se reúnen en un marco formal institucional en forma representativa y democrática.

En una tercera etapa dicho cuerpo colegiado debatirá, negociará y aprobará en una asamblea constituyente un texto que recoja el consenso y acuerdo necesario.

En una cuarta etapa dicho texto será objeto de ratificación o rechazo por la ciudadanía del texto elaborado por sus representantes a través de un referéndum democrático, el cual además puede establecer la aprobación por separado de los capítulos o párrafos del texto constitucional.

\section{Poder constituyente instituido o derivado}

El poder de reforma de la Constitución está sometido a la Carta Fundamental y pueden sus actos ser objeto de control de constitucionalidad por el órgano jurisdiccional encargado de velar por la defensa de la Constitución y la idea de derecho válida contenida en la misma.

El poder constituyente instituido o constituido con potestad para reformar la Carta Fundamental se encuentra subordinado al poder constituyente originario y por encima de los demás poderes estatales (Gobierno, Congreso, Poder Judicial), ya que la existencia, funciones y atribuciones de estos últimos pueden ser objeto de revisión constitucional, pero el poder de reforma constitucional debe respetar en tales reformas los limites formales y materiales impuestos por la Carta Fundamental, debe operar dentro de marco de competencias fijado por la Constitución.

Así Pedro De Vega señala «un hecho que, como punto de partida, a la hora de fijar la naturaleza del poder de reforma, no admite discusión posible, es que se trata de un poder regulado y ordenado en el texto constitucional. En él basa su competencia» $^{10}$.

El poder de reforma constitucional reconoce las limitaciones jurídicas que la propia Constitución dispone, aun cuando su producto normativo tiene la misma naturaleza y fuerza normativa de la Constitución.

8 Heller, H., Teoría del Estado. Sexta reimpresión. México, FCE, 1971, p. 277.

9 Mortati, C., «Appuntisul problema dellafonte del potereCostituente», en Raccolta di scritti, Vol. I, Milan, Ed Dott. A. Giuffre, 1972, p. 358.

10 De Vega García, P., op. cit., p. 236. 
La alteración sustantiva de la idea de derecho y principios estructurales básicos contenidos en la Constitución, sin participación directa del cuerpo político de la sociedad es inválida por carecer de legitimidad para modificar la idea de derecho contenida en la Carta Fundamental, la cual corresponde únicamente a dicho cuerpo político.

Como ya sostenía incluso Carl Schmitt la facultad de reformar la Constitución, «atribuida a una formación legal-constitucional, significa que una o varias regulaciones legal-constitucionales pueden ser sustituidas por otras regulaciones legal-constitucionales, pero sólo bajo el supuesto que queden garantizadas la identidad y continuidad de la Constitución considerada como un todo: la facultad de reformar la constitución contiene, pues, tan sólo la facultad de practicar, en las prescripciones legal-constitucionales, reformas, adiciones, refundiciones, supresiones, etc., pero manteniendo la Constitución» ${ }^{11}$.

Ello lleva a afirmar que el poder de reforma constitucional no puede sustituir al poder constituyente originario, alterando la idea de derecho, la fórmula política o principios supremos establecidos constitucionalmente por el constituyente originario, el poder de reforma constitucional sólo puede operar dentro de los principios supremos del orden constitucional o formula política establecida por el constituyente originario, sin poder sustituirla o abrogarla ${ }^{12}$.

Las reformas parciales o totales de la Constitución en cuanto expresiones de un poder instituido por la Constitución deben desarrollar su tarea dentro de la Constitución, teniendo un carácter limitado tanto formal como materialmente, conforme a los principios básicos del constitucionalismo democrático, ya que no es un poder libre y soberano y se encuentra sometidos a los principios democrático y de supremacía constitucional, los que no pueden ser afectados por una reforma constitucional.

11 Schmitt, C., Teoría de la Constitución. Madrid, Ed. Alianza, 1982, p. 119.

12 Linares Quintana, S.V. Tratado de la Ciencia del Derecho Constitucional. Tomo II, Buenos Aires, Ed. Alfa, 1953, p. 130. SÁnchez Viamonte, C., El poder constituyente. Buenos Aires. Ed. bibliográfica argentina,1957, p. 576. Desde un punto de vista jurisprudencial versentencia de la Corte Constitucional italiana $n .^{\circ} 1146$ de 1988, que identifica los limites naturales de la reforma constitucional con los principios supremos del ordenamiento constitucional; ver también sentencias n. ${ }^{\circ} 30$ del $1 .^{\circ}$ de marzo de 1971 ; n. ${ }^{\circ} 175$ del 11 de diciembre de 1975 y n. ${ }^{\circ} 1146$ de 1998. En forma similar, el Tribunal Constitucional peruano en la sentenciaExp. $n .^{\circ}$ 050-2004-AI/TC y otros, la cual reconoce limites materiales expresos y tácitos de la reforma constitucional. La Corte Suprema argentina, en sentencia de 19 de agosto de 1999, en la causa Fayt, Carlos Santiago vs. Estado Nacional, admitió la plena justiciabilidad de la reforma constitucional tanto en sus ámbitos procedimentales sino en cuanto a los ámbitos sustantivos o materiales de una reforma, siendo el límite expreso o implícito. Sobre la materia se encuentra también la sentencia de la Corte Constitucional de Colombia, C-551 de 2003, cuyo fundamento 37 señala que un poder de reforma sin límites competenciales elimina también la distinción entre el poder constituyente originario y el poder constituyente derivado o de reforma.(...) En este orden de ideas, se entiende que el poder constituido (que incluye el poder de reforma de la Constitución), únicamente tiene existencia a partir del hecho constituyente y en los términos definidos por las decisiones fundamentales tomadas por el poder constituyente. (...) El poder constituido, no puede (...) arrogarse funciones propias del poder constituyente, y por ello no puede llevar a cabo una sustitución de la Constitución, no sólo porque se estaría erigiendo en poder constituyente originario, sino porque está minando las bases de su propia competencia». 
Como señala Ruipérez siguiendo a De Vega, cuando la reforma «se concibe como obra de un poder soberano en el objeto, aunque se presente como constituido y limitado en el procedimiento, la propia institución de la reforma constitucional, en cuanto expresión de la continuidad jurídica del ordenamiento deja de tener sentido ${ }^{13}$. Como precisara Pedro De Vega, «un poder limitado sólo en la forma pero libre en el ejercicio de su voluntad, con capacidad de cambiar todos los principios, valores y normas que fundamentan ideológicamente el sistema, termina siendo el auténtico soberano» ${ }^{14}$.

El poder constituyente instituido nunca puede transformarse en poder constituyente, ni aún en el caso de preverse una posible reforma total por el texto constitucional, ya que la potestad reformadora para ser válida y legítima tiene como límite ineludible, el núcleo esencial de la Constitución ${ }^{15}$, como límite material implícito o explícito, ya que el poder reformador obtiene su legitimidad de la Constitución vigente, no pudiendo desarrollar una nueva legitimidad constitucional, ya que ello convierte a la juridicidad del Estado Constitucional democrático en un instrumento legitimador de la ruptura constitucional, un acto revolucionario, que generaría un nuevo régimen político y constitucional.

Si en vez de reformar la Constitución, la sociedad política desea un nuevo orden político y jurídico, una nueva legitimidad constitucional, que no tenga los límites de un poder reformador de la constitución, concretando un acto revolucionario, debe dar paso al pueblo soberano, a la autonomía del cuerpo político de la sociedad, el que deberá actuar como un nuevo poder constituyente originario (res facti, non juris), libre en la determinación de su objeto, no sometido a la juridicidad de la Constitución hasta entonces vigente, libre para decidir las instituciones, modos y formas en que dicha sociedad será gobernada en el futuro, pero dicho poder constituyente debe actuar a través de un órgano que exprese dicha soberanía popular, cuya actuación debe ser ratificada por el titular de dicha soberanía y del poder constituyente que es el pueblo, único cuerpo político de la sociedad política llamado a decidir las instituciones, modos y formas que deben adoptar su Carta Fundamental y a controlar los actos de sus representantes, a través de un referéndum sobre el nuevo texto constitucional, aceptando o rechazando las propuestas de sus representantes, los que nunca están autorizados para

13 Ruipérez Alamillo, J., Reforma versus revolución. Consideraciones desde la Teoría del Estado y de la Constitución sobre los límites materiales a la revisión constitucional. México D.F. Editorial Porrúa, 2014, p. 191.

14 De Vega, P., op. cit., pp. 229-230.

15 Zagrebelsky, G., Il sistema constituzionaledellefonti del diritto.Turin, UTET, 1984, pp. 100-104. Hesse, K., «Concepto y cualidad de la Constitución», Escritos de Derecho Constitucional, Madrid, CEC, 1983, especialmente pp. 276-279. BARILe, P., op. cit., p. 445. Calzada Conde, R., La reforma constitucional y las mutaciones en el ordenamiento constitucional. Tesis doctoral, Vol. II. Salamanca, 1987, Vol. II, p. 842. DE OTTO, I., Defensa de la Constitución y partidos políticos. Madrid, CEC, 1985, pp. 29-30. DE VEGA, P., op. cit., pp. 283284; LuCas Verdú, P., Teoría jurídica de los cambios constitucionales. Curso de Derecho Político II. Segunda edición, Madrid, Tecnos, 1977, pp. 650 y ss. Morodo, R., Teoría jurídica de los cambios constitucionales. Curso de Derecho Político II. Segunda edición, Madrid, Tecnos, 1969, p. 222. 
sustituir al sujeto titular del poder constituyente, único legitimado para aprobar la Constitución.

Tal perspectiva se constituye en jurídica y políticamente válida y conveniente si la Constitución ya no responde a los valores y a la idea de derecho válida y vigente en la sociedad, cuando la mayoría del cuerpo político cuestiona la validez de la Constitución.

\section{LA REFORMA DE LA CONSTITUCIÓN CHILENA VIGENTE}

En el caso chileno, la Carta Fundamental, en su texto reformado de 2005, regula la materia en su capítulo $\mathrm{XV}^{16}$.

\section{Iniciativa de reforma constitucional}

El artículo 127 de la Constitución chilena determina quienes tienen iniciativa de reforma constitucional, precisando que ellos son el Presidente de la República mediante mensaje y los parlamentarios por moción, en el caso de los diputados estas mociones no pueden ser firmadas por más de diez diputados o más de cinco senadores ${ }^{17}$.

\section{Quórum de aprobación de las reformas constitucionales, conforme} a procedimiento ordinario o extraordinario

El proyecto de reforma constitucional necesita para ser aprobado en cada Cámara, conforme al inciso $2 .^{\circ}$ del artículo 127 , el voto conforme de las tres quintas partes de los diputados y senadores en ejercicio. Este es el quórum requerido para la reforma ordinaria del texto de la Constitución, sin embargo, el mismo inciso determina un procedimiento extraordinario de reforma constitucional, el cual se aplica a los contenidos de diversos capítulos de la Constitución, ellos son el capítulo I de Bases de la Institucionalidad; el capítulo III de Derechos y Deberes Constitucionales; el capítulo VIII, referente a composición y atribuciones del Tribunal Constitucional; el Capítulo XI referente a las Bases constitucionales de las Fuerzas Armadas, de Orden y Seguridad Públicas; el capítulo XII correspondiente a la composición y funciones del Consejo de Seguridad Nacional; o al capítulo XV referente al proceso de reforma constitucional, los cuales necesitan

16 Nogueira, H., Derecho constitucional chileno. Tomo III. Santiago, Ed. Abeledo Perrot — Thomson Reuters, 2014, pp. 517-522.

17 La Cámara de Diputados está compuesta actualmente de 120 diputados y el Senado de 38 senadores. 
para ser reformados de, la concurrencia de, al menos, dos tercios de los diputados y senadores en ejercicio.

Los proyecto de reforma constitucional conforme al artículo 26 de la LOC del Congreso Nacional pueden ser objeto de calificación de urgencia por parte del Presidente de la República en uno o en todos sus trámites, en el correspondiente mensaje o mediante oficio que dirigirá al presidente de la Cámara en que se encuentre el proyecto, o al Senado cuando el proyecto estuviere en comisión mixta. En el mismo documento expresará la calificación de la urgencia, la que podrá ser simple, suma o discusión inmediata, si no se especificare la urgencia ella será simple.

Como señala el artículo 27 de la LOC del Congreso, la urgencia simple, implica que la discusión y votación de la Cámara requerida deberá quedar terminada en el plazo de treinta días, si la calificación fuere de suma urgencia, este plazo será de quince días, y si se determinare discusión inmediata el plazo será de seis días.

Conforme al artículo 28 de la Ley en comento, en caso de simple urgencia, la comisión mixta dispondrá de diez días para informar el proyecto, que es el mismo plazo que tiene cada una de las Cámaras del Congreso Nacional para despachar el informe de Comisión Mixta. En el caso de discusión inmediata, el plazo es de dos días para comisión mixta y dos días para su despacho por cada cámara.

\section{Sanción o veto total o parcial del Presidente de la República sobre el proyecto de reforma constitucional aprobado por el Congreso Nacional}

El proyecto aprobado por ambas cámaras pasa, luego, al Presidente de la República, el cual puede aprobar o rechazar, en este último caso, total o parcialmente la reforma constitucional aprobada por el Congreso Nacional.

En el caso de que el proyecto de reforma constitucional sea aprobado por el Presidente de la República en los mismos términos aprobados por el Congreso, luego debe promulgar el texto sancionado, dictando el decreto promulgatorio, el cual una vez totalmente tramitado por la Contraloría General de la República, debe ordenarse su publicación en el Diario Oficial, la que debe concretarse en los cinco días hábiles siguientes.

\section{Procedimiento ante el veto total o parcial de la reforma aprobada por el Congreso}

Si el Presidente de la República rechaza totalmente el proyecto de reforma constitucional aprobado por el Congreso Nacional, lo que constituye un veto suspensivo total, el proyecto vuelve al Congreso Nacional para un nuevo pronunciamiento de éste, el cual puede insistir en la reforma ya aprobada por el mismo por las dos terceras partes de cada una de sus ramas, Cámara de Diputados y Se- 
nado, en cuyo caso el Presidente se 3 encuentra obligado a promulgar dicho proyecto de reforma a menos que consulte a la ciudadanía mediante plebiscito, según determina el artículo 128 , inciso $2 .^{\circ}$ de la Constitución.

Si el Presidente de la República vetare parcialmente un proyecto de reforma constitucional aprobado por el Congreso Nacional, las disposiciones observadas deben ser objeto de un nuevo pronunciamiento del Congreso Nacional, el cual puede aprobar las observaciones hechas por el Jefe de Estado con el voto conforme de los tres quintos o de los dos tercios de los miembros en ejercicio de cada cámara, según corresponda a materias de procedimiento ordinario o extraordinario de reforma constitucional. Si ello ocurre el proyecto es devuelto al Presidente para su promulgación y posterior publicación en el Diario Oficial, conforme determina el artículo 128 , inciso $3 .^{\circ}$ de la Constitución.

En el caso de que las Cámaras no aprueben todas o algunas de las observaciones o vetos formulados por el Jefe de Estado, producido el desacuerdo entre ambos órganos que participan de la potestad reformadora de la Constitución, no habrá reforma en los puntos en que se ha expresado la discrepancia, a menos que, ambas ramas insistan en el proyecto de reforma aprobado por ellas por dos tercios de sus miembros en ejercicio. En tal caso, se devolverá al Presidente la parte del proyecto de reforma constitucional que ha sido insistido por el Congreso, debiendo promulgarlo, salvo que éste ejerza la facultad de llamar a plebiscito para que la ciudadanía se pronuncie respecto de las cuestiones en desacuerdo entre ambos órganos constitucionales, todo ello conforme al artículo 128 , inciso $4 .^{\circ}$ de la Constitución.

La Ley n. ${ }^{\circ} 18918$, Orgánica Constitucional del Congreso Nacional, regula la tramitación de los vetos del Presidente de la República a los proyectos de reforma constitucional en su título III. Ella determina que tales vetos sólo pueden admitirse a tramitación cuando tengan relación directa con las ideas matrices o fundamentales del proyecto de reforma constitucional, a menos que dichas ideas hayan sido consideradas en el proyecto de reforma presentado por el Presidente de la República (mensaje), conforme al artículo 32 de esta ley. Corresponde al Presidente de la Cámara de origen la facultad de declarar la inadmisibilidad de tales observaciones o vetos. El hecho de estimarse admisibles los vetos en la Cámara de origen no obstan a la facultad del presidente de la cámara revisora para declarar la inadmisibilidad.

En los dos casos señalados, la sala de la Cámara que corresponda podrá reconsiderar la declaración de inadmisibilidad efectuada por su presidente. La circunstancia de que no se haya declarado la inadmisibilidad no impide a las comisiones poder realizar tal declaración, la que podrá ser revisada por la sala de la Cámara respectiva, todo ello conforme al artículo 32 de la LOC del Congreso Nacional

Los artículos 33 y 34 de la LOC del Congreso Nacional precisan que los vetos deben ser votados por las respectivas cámaras, en el caso de veto total, sólo se vota si se insiste en la totalidad del proyecto, bastando que una sola de las Cámaras no alcanzare la mayoría de dos tercios de sus miembros en ejercicio para que 
se entienda terminada la tramitación del proyecto. Si el veto es parcial, se deben producir dos votaciones diferentes, la primera destinada a determinar si las respectivas cámaras aprueban o rechazan cada uno de los vetos formulados; y la segunda, destinada a resolver si, en el caso de rechazo de algunas observaciones o vetos, la Cámara insiste o no en la mantención de la parte observada.

El artículo 35 de la LOC del Congreso determina que cada observación formulada por el Presidente de la República al proyecto de reforma constitucional, debe ser aprobada o rechazada en su totalidad, no procediendo dividir la votación para aprobar o rechazar sólo una parte de ella. Sea esta un título, un capítulo, un párrafo, un artículo, un inciso, un literal o numeral u otra división del proyecto.

\section{El cuerpo político de la sociedad como árbitro de las discrepancias entre el Congreso y el Presidente de la República}

Conforme al artículo 129 de la Carta Fundamental, el Presidente de la República dispone de la facultad de convocar a plebiscito para que el cuerpo político de la sociedad dirima entre las posiciones divergentes del Presidente de la República y del Congreso Nacional en materia de reforma constitucional, cuando el Presidente ha vetado una reforma constitucional aprobada por el Congreso y éste último ha rechazado el veto total o los vetos parciales e insistido en el proyecto de reforma originalmente aprobado por ambas ramas del Congreso. En el caso de que el Presidente opte por la convocatoria a plebiscito, éste deberá efectuarse dentro de los treinta días siguientes a aquel en que ambas ramas del Congreso Nacional hayan insistido en el proyecto aprobado por ellas, y se ordenará mediante decreto supremo que fijará la fecha de la votación plebiscitaria la que se realizará ciento veinte días después de la publicación de dicho decreto si ese día correspondiere a un domingo. Si así no fuere, ella se realizará el domingo inmediatamente siguiente. Si habiendo transcurrido dicho plazo, el Presidente no hubiese convocado a plebiscito, debe promulgarse el proyecto de reforma constitucional que hubiere aprobado el Congreso.

\section{El decreto de convocatoria del Plebiscito y control de constitucionalidad}

El decreto de convocatoria a plebiscito que dicta el Presidente de la República debe contener, según corresponda, el proyecto aprobado por ambas cámaras del Congreso Nacional y vetado totalmente por el Jefe de Estado, o las cuestiones del proyecto en las cuales el Congreso haya insistido. En este último caso, cada una de las cuestiones en desacuerdo deberá ser votada separadamente en el plebiscito, conforme determina el artículo 129 inciso 2. ${ }^{\circ}$ de la Carta Fundamental.

Cabe señalar que este decreto de convocatoria a plebiscito puede ser objeto de un requerimiento de inconstitucionalidad ante el Tribunal Constitucional, 
conforme al artículo 93 N. ${ }^{\circ} 5$ de la Constitución, en el caso, por ejemplo, de que las preguntas no sean formuladas en términos objetivos, sin inducir a los electores a votar por una de las alternativas en juego, o por incumplir alguno de los plazos o procedimientos determinados constitucionalmente.

El Tribunal Constitucional en Pleno conoce de la materia, la que debe promoverse dentro de un plazo de diez días, contados desde la publicación del decreto que fije el día de la consulta plebiscitaria. Dicho requerimiento puede ser promovido por la Cámara de Diputados o por el Senado. El Tribunal Constitucional establecerá en su resolución el texto definitivo de la consulta plebiscitaria, cuando esta fuere procedente. En el caso que al dictarse la sentencia por parte del Tribunal Constitucional faltare menos de treinta días para la realización del plebiscito, éste fijará en dicho fallo una nueva fecha comprendida entre los treinta y sesenta días siguientes al fallo.

\section{Resultado del plebiscito de reforma constitucional}

Corresponde al Tribunal Calificador de Elecciones comunicar al Presidente de la República, conforme determina el artículo 129 , inciso $3 .^{\circ}$ de la Constitución, el resultado del plebiscito y especifica el texto del proyecto aprobado por la ciudadanía, el que deberá ser promulgado como reforma constitucional dentro de los cinco días siguientes a dicha comunicación.

Promulgado el proyecto de reforma constitucional, desde la fecha de su vigencia sus disposiciones forman parte de la Constitución y se tienen por incorporadas a ella.

\section{Control de constitucionalidad preventivo sobre proyectos de reforma constitucional}

El artículo 93 n. ${ }^{\circ} 3$ de la Constitución le entrega como competencia al Tribunal Constitucional «Resolver las cuestiones sobre constitucionalidad que se susciten durante la tramitación de una reforma constitucional». El Tribunal sólo puede conocer de la materia a requerimiento del Presidente de la República, de cualquiera de las Cámaras o de una cuarta parte de sus miembros en ejercicio, siempre que sea formulado antes de la promulgación de la ley de reforma constitucional y, en caso alguno, después de quinto día del despacho del proyecto por el Congreso.

A través de dicho procedimiento se pueden impugnar todo incumplimiento de ámbitos procedimentales o de competencia de los órganos que intervienen en la reforma constitucional. Asimismo se debate si a través de dicho control el Tribunal Constitucional puede desarrollar control sustantivo sobre los ámbitos que constituyen la identidad y continuidad de la Constitución considerada como un todo o sus principios supremos. 
En tal perspectiva, Alejandro Silva Bascuñán, en su Tratado de Derecho Constitucional, determinaba:

«Si la Carta de 1980 precisa que «el ejercicio de la soberanía reconoce como limitación el respeto a los derechos esenciales que emanan de la naturaleza humana» (Art. 5..$^{\circ}$ inc $2 .^{\circ}$ ), el Poder constituyente instituido o derivado, al reformar la Carta, no puede prescindir de la valla sustancial que ha tenido en cuenta el constituyente, por cuya autoridad se estableció el Estatuto Básico y se ha venido completando y adaptando. Esta conclusión evidente tendrá que ser fundamento ineludible para que el Tribunal Constitucional repare un proyecto de reforma que pugne con los derechos esenciales del hombre».

«Por otra parte, las decisiones de Chile como país soberano, expresándose en el ejercicio del Poder constituyente instituido, que actúa a través de la aprobación de un proyecto de reforma constitucional, no pueden vulnerar tampoco las restricciones que derivan tanto del derecho internacional convencional como del consuetudinario; esta fuente de restricción dará también al Tribunal Constitucional otra pauta a la que habrá de ajustarse al examinar un proyecto de reforma en el que haya surgido la cuestión de constitucionalidad por sentenciar» ${ }^{18}$.

Señalemos que el Tribunal Constitucional también ha determinado en sentencia Rol n. ${ }^{\circ}$ 1218-08-INA, de siete de julio de dos mil nueve, que:

«Que el sistema institucional vigente en Chile se articula en torno de la dignidad que singulariza a todo sujeto de la especie humana, siendo menester poner de relieve que si la Carta Política asegura a todas las personas los derechos fundamentales, lo hace en el entendido que preexisten a ella; y que, en armonía con lo preceptuado en el artículo 5. ${ }^{\circ}$, inciso segundo, los órganos públicos y los agentes privados, cada cual en ejercicio de la competencia y facultades que les han conferido, respectivamente, la Constitución y la ley, no sólo están obligados a respetar esos derechos, sino que, además, a protegerlos y promoverlos» ${ }^{19}$.

\section{EL PROCESO DE CAMBIO CONSTITUCIONAL EN CHILE}

En el caso chileno sobre el $70 \%$ de la ciudadanía, a través de mediciones hechas en diversas encuestas, plantea la necesidad de un cambio constitucional o de una Constitución, una Constitución para el siglo xxI, que sea la expresión auténtica del cuerpo político de la sociedad chilena. Se afirma así que no es ade-

18 Silva Bascuñán, A., Tratado de derecho constitucional. Segunda edición. Tomo X, Ed. Jurídica de Chile, Santiago, 2004, p. 264.

19 Sentencia del Tribunal Constitucional Rol n. ${ }^{\circ}$ 1218-08-INA, de siete de julio de dos mil nueve, considerando $18 .^{\circ}$. 
cuado ni conveniente seguir parchando una Carta Fundamental emanada de un régimen autocrático de tipo autoritario burocrático militar.

Ello fue planteado como tema de campaña en las elecciones presidenciales y como objetivo de la candidatura de la actual Presidenta de la República Michelle Bachelet Jeria, el que debería concretarse durante su gobierno.

En tal perspectiva, el martes 13 de octubre de 2015, la Presidenta de la República anunció el cronograma del cambio constitucional. En dicho cronograma estableció una etapa de educación cívica que se llevaría adelante hasta marzo de 2016, consistente en socializar a la población acerca de las funciones que cumple una Constitución en una sociedad democrática a través de información en páginas web y textos explicativos, el que se encuentra en pleno desarrollo al momento de escribir el presente trabajo.

El 2 de diciembre de 2015, la Presidenta Bachelet, nombró un Consejo Ciudadano de Observadores del Proceso Constituyente, el cual debe «garantizar la transparencia de los diálogos ciudadanos» que se desarrollarían a nivel comunal y regional, el cual está integrado por 17 integrantes del mundo civil, de las comunicaciones, y expertos constitucionalistas expresivos del pluralismo nacional en el ámbito ideológico,presidido por el abogado constitucionalista Patricio Zapata, cuya tarea consiste en garantizar que las instancias de participación a nivel comunal, provincial y regional se lleven a cabo de manera transparente, recogiendo las opiniones de los ciudadanos sin presiones ni distorsiones.

Asimismo, desde el domingo 24 de enero de 2016 hasta el 12 de febrero de 2016 se abrió concurso público por el Servicio Civil, al que podrán participar quienes deseen ser parte del proceso constituyente como «facilitadores» de los cabildos ciudadanos.Se elegirán 216 facilitadores, de los cuales 54 corresponderán al nivel central para apoyar procesos específicos fuera de la programación provincial, y 162 conformarán equipos de tres facilitadores en cada una de las 54 provincias del país. El análisis curricular de los postulantes comenzará inmediatamente concluida esta etapa y culminará el 22 de febrero. La de evaluación de candidatos se cierra el 9 de marzo y la calificación de los candidatos se extiende hasta el 16 de marzo.El proceso se finaliza con la propuesta y designación de dichos monitores o facilitadores que cierra el 28 de marzo, existiendo un plazo adicional de cinco días sobre reclamos en dicho proceso de nombramiento. El número de monitores que se designarán son un total de 216, de ello 54 corresponderán al nivel central para apoyar procesos específicos fuera de la programación provincial, y 162 conformarán equipos de tres facilitadores en cada una de las 54 provincias del país. Los concursantes pueden estar afiliados a un partido político, pero no podrán participar en el concurso dirigentes políticos nacionales o regionales de los partidos, autoridades de gobierno y funcionarios del Estado, asimismo se inhabilitan para desempeñar tales funciones los alcaldes, concejales y consejeros regionales, y personas que sean candidatos a dichos cargos en 2016. Dichos monitores o facilitadores de los diálogos ciudadanos en cabildos territoriales serían contratados por un periodo de cuatro meses, sin dedicación exclusiva. 
Estos monitores se clasifican en tres grupos, el primero constituido por coordinadores territoriales de facilitación y ejecución de diálogos locales; un segundo grupo de especialistas legales, que deben ser licenciados en Ciencias jurídicas o abogados, encargados de asesorar a la provincia en las materias atingentes al proceso constituyente, siendo el soporte técnico para el equipo territorial en los ámbitos de su competencia; y un tercer grupo de especialistas en la sistematización del diálogo, cuyo objetivo es el de ejecutar, mantener y controlar los registros de las distintas actividades relacionadas al proceso constituyente, correspondientes a su territorio, debiendo tener una formación avanzada en gestión de bases de datos.

Desde el mes de abril hasta el mes de agosto de 2016 se concretó la etapa de diálogos ciudadanos a través de los cuales se recogieron las Bases ciudadanas para una nueva Constitución que contendrían las ideas fuerzas y proposiciones que debiera considerar la nueva Constitución, las que se entregarían a la Presidenta de la República en octubre de 2016.

En estos diálogos participaron todas las personas desde los 14 años. Se trata de un proceso de cuatro fases, en que se discutirá sobre valores y principios, derechos, deberes y responsabilidades, e instituciones que debe contemplar la Constitución.

Para participar en la primera fase, hubo dos caminos. El primero es llenar un cuestionario online; el segundo es participar en un grupo conducido por un monitor, pudiendo participar las personas en ambos procesos.

En dicho proceso se les preguntó a las personas, en primer lugar, sobre cuáles de 19 valores consideran más importantes y se encuentra también la alternativa de ningún valor. Luego, se les preguntará sobre los derechos más importantes de un listado de 26 de ellos, como asimismo sobre los principales deberes de una lista de 21 de ellos. Finalmente se les consultará sobre las instituciones que deberá contemplar la Constitución.

Los resultados de estos diálogos fueron sistematizados a través de un software y las principales conclusiones dieron origen a un nuevo diálogo ciudadano que se desarrolló a nivel provincial. Esa segunda fase dio paso a una tercera, en que tras una nueva sistematización de los antecedentes, se realizaron los diálogos a nivel regional que se concretaron el sábado 6 de agosto, para que, luego de una última sistematización de los antecedentes, que a esta fecha se encuentra aún en proceso, se entregarán a la Presidenta de la República.

A fines del año 2016 o en el curso del año 2017, la Presidenta de la República enviará una reforma constitucional que recogerá las bases ciudadanas para la nueva Constitución, junto con las tradiciones nacionales y «acorde con las obligaciones jurídicas que Chile ha contraído con el mundo» como ha señalado la Presidenta Bachelet, que contendría la modificación a la Constitución actual. Asimismo, en dicha reforma constitucional se decidiría por el actual Congreso Nacional una reforma constitucional que pueda viabilizar al próximo Congreso Nacional la decisión sobre las diversas opciones procedimentales para debatir la 
nueva Constitución; decisión que debiera ser adoptada por acuerdo de ambas ramas del actual Congreso Nacional por el quórum de 2/3 de los parlamentarios en ejercicio de cada cámara (al menos 80 diputados y 25 senadores).

Será el próximo Congreso Nacional, electo en noviembre de 2017, con un sistema de representación proporcional con método apostrofe D'Hondt, el que dotado de mayor representatividad, decidirá el mecanismo a través del cual se desarrollará el cambio constitucional.

Así la campaña electoral del segundo semestre de 2017 de elecciones presidenciales y parlamentarias debiera darse en un clima de debate por el cambio constitucional, sobre el cual debieran pronunciarse las diversas candidaturas y partidos.

El nuevo Congreso que asumirá el 11 de marzo de 2018,estaría habilitado para decidir entre cuatro alternativas el mecanismo procedimental de debate y aprobación de la reforma constitucional o de nueva Constitución. Estas alternativas de mecanismos para debatir y aprobar la nueva Constitución serían: A) una Comisión Bicameral del Congreso Nacional; B) Una Convención Constituyente mixta de parlamentarios y ciudadanos; una Asamblea Constituyente; o un plebiscito para que sea la ciudadanía la que determine el mecanismo entre las tres opciones anteriores.

Cualquiera fuere el procedimiento por el que se opte en su oportunidad, el proceso constituyente terminará con un plebiscito o referéndum en que la ciudadanía se pronunciará aprobando o rechazando el texto de nueva Constitución.

La opción de una Comisión bicameral mixta de diputados y senadores constituye una alternativa que opera en el marco de una reforma a la Constitución vigente, ya que el texto constitucional actual no establece dicho procedimiento para tramitar una reforma constitucional, debiendo introducirse y regularse este órgano en el capítulo de reforma de la Constitución, aún cuando los parlamentarios integrantes de la Comisión aludida habrían sido elegidos de acuerdo al texto constitucional vigente. No hay claridad sobre si los parlamentarios, además de sus funciones constituyentes instituidas, desarrollarían simultáneamente sus funciones legislativas.

La opción de la Convención mixta de parlamentarios y ciudadanos implica un procedimiento constituyente no contemplado actualmente en el texto constitucional, en el cual el órgano que debatiría el texto de nueva Constitución, tendría una composición mixta, estando integrado de diputados y senadores, no precisándose si por todos los diputados y senadores o por una proporción de los electos en 2017, sin que exista tampoco una precisión del porcentaje de ciudadanos electos para integrar el órgano constituyente en relación al de los parlamentarios que lo integrarían, ni los distritos, circunscripciones o eventuales listas nacionales por la que ellos serían elegidos.

La opción por una asamblea constituyente conforma claramente una opción que implica el ejercicio de un poder constituyente originario para establecer una nueva Constitución, lo que requiere de una determinación previa de su número 
de integrantes, procedimiento de elección, procedimiento de adopción de decisiones al interior de la Asamblea.

La cuarta opción es que los parlamentarios se pronuncien por que la decisión acerca de cualquiera de las tres opciones anteriores sea adoptada no por ellos, en cuanto representantes de la ciudadanía, sino directamente por la ciudadanía que detenta el poder constituyente originario de la sociedad política, así el cuerpo político de la sociedad determinaría si serían sus representantes parlamentarios a través de una reforma constitucional; una comisión mixta de parlamentarios y de ciudadanos electos al efecto o una asamblea constituyente la que debiera elaborar y aprobar el texto constitucional. En la primera opción, al menos, la ciudadanía determinaría el ejercicio de un poder constituyente derivado, mientras que en la segunda y tercera opciones habría decidido por el ejercicio de un poder constituyente originario.

En definitiva, será el nuevo Congreso Nacional electo en 2017, electo con un sistema de representación proporcional con método D Hondt, el que determinará el mecanismo a través del cual se desarrollará el cambio constitucional, el que debería ser aprobado por 3/5 de los parlamentarios en ejercicio de cada cámara. Así este determinaría si habría un proceso constituyente originario o un proceso de reforma de la Constitución o si entrega dicha determinación directamente a la ciudadanía mediante un referéndum.

Asimismo, el desarrollo de este proceso de cambio constitucional, una vez concretada la primera reforma que rebaja el quórum de reforma constitucional de $2 / 3$ a $3 / 5$ de los diputados y senadores en ejercicio que debiera ser aprobada en 2017 por el actual Congreso Nacional, quedará entregado, en la práctica, a la decisión ciudadana que elegirá el nuevo Congreso Nacional a fines de 2017, con una nueva conformación del mismo, de acuerdo con los nuevos distritos y circunscripciones y con el aumento de número de diputados y senadores que integrará cada cámara; pasando la Cámara de Diputados de 120 a 155 diputados, los que, para mejorar su representatividad, serán elegidos en 28 distritos en vez de los 60 en que fueron electos los actuales diputados, como asimismo por un Senado de 50 senadores en vez de los 38 actuales, existiendo una sola circunscripción por cada región del país, producto de la reforma electoral ya aprobada en 2015. Será así el nuevo Congreso Nacional que iniciará su actividad el 11 de marzo de 2018 el que adoptará las decisiones fundamentales que darán viabilidad o no al proceso constituyente originario o a otra gran reforma constitucional después de las de 1989 y 2005.

\section{$* * *$}

Title: Democracy, Constituent Power or Constitutional Reform and its legal Implications in the Political Process of Constitutional Reform in Chile

ABSTRACT: This paper analyses the constitutional reform process in Chile. This process is characterized by the civil participation in local meetings. This civil initiatives advance to provincial and regional organ- 
isms, whose central ideas will be the bases to elaborate and present institutionally to the National Congress the constitutional reform and the modification of the constitutional procedure. The next National Congress, elected at the end of 2017, will decide about the reform proposal given the definitive decision of the citizenship by a referendum.

RESUMEN: El presente artículo reflexiona sobre un enfoque teórico de un proceso constituyente originario o instituido en un marco institucional democrático, dentro del cual se analiza y describe el proceso constituyente iniciado en Chile, el cual tiene como característica inicial la participación ciudadana en encuentros locales, para luego avanzar el cabildos provinciales y regionales, cuyas ideas centrales serán las bases en virtud de las cuales la actual Presidenta de la República elaborará y presentará institucionalmente al Congreso Nacional su propuesta de reforma constitucional y de modificación del procedimiento constitucional que posibilite decidir al próximo Congreso Nacional, elegido a fines de 2017 y que entra en funciones el 11 de marzo de 2018, entre diversos mecanismos institucionales para procesar y aprobar una reforma o un cambio de Constitución, el que en cualquiera de sus alternativas deberá considerar la decisión definitiva de la ciudadanía a través de un referéndum.

KeY wORDS: Constituent process, Chile, Constitutional Reform Proposal.

Palabras clave: Proceso constituyente. Chile. Propuesta de reforma constitucional.

FECHA DE RECEPCIÓN: 02.02.2016

FECHA DE ACEPTACIÓN: 27.07.2016 